\title{
Relationship between Research, Innovation and Development - a Review
}

\author{
Stephen O. Ekolu \\ Department of Civil Engineering Science, University of Johannesburg, \\ Auckland Park 2006, South Africa \\ sekolu@uj.ac.za, sekolu@gmail.com
}

\begin{abstract}
In this paper, data are used to show that countries with high record of publications and patents are either developed or those countries that are strongly developing. Mastery of existing scientific knowledge and intensification of engineering and scientific research emerge as the two important ingredients that are necessary for industrial development. Current trends in research show inklings of research growth in SubSaharan Africa. However, the limited growth in research at an advanced level is presently a critical barrier and a major challenge.
\end{abstract}

Keywords: Research, gross domestic product, patents, articles, engineering and technology, innovation, development

\section{Introduction}

Since the industrial revolution which commenced in the $18^{\text {th }}$ century, modern economic development is primarily based on industrialization. Accordingly, sciences, engineering and technology fields (SE\&T) are primary drivers of industrial development and creation of manufactured products, through research and innovation. Accordingly, those economies that excel in naturing and exploiting the SE\&T fields, also become advanced relative to the others that have not equally prioritised scientific research and innovation. It should, however, be remembered that peace, good governance, absence of corruption, and activism of civil society, are considered to be essential pre-requisites for development to flourish[1].

Recent trends in SubSaharan Africa (SSA) have promoted massification of education, prompted by United Nations millenium development goals, as opposed to the traditional approach for which only few people would access educational opportunities. Massification has led to expansion of higher education sector across SSA with an $8.6 \%$ increase in enrolments over a 38-year period between 1970 and 2008. This high growth by far exceeds the global average of $4.6 \%$. These results are attributed to deliberate increase in number of both public and private higher education institutions (HEIs) within SSA [2,3]. However, Africa still lags behind all other regions of the world, having only $6 \%$ of the eligible population being enrolled at HEIs as opposed to the world average of $26 \%$.

The gross domestic product (GDP) of SSA has grown at a rate of 4 to $6 \%$ over the past 14 years. But it is essential to carefully consider the drivers of present growth. Analysis [4] shows that present growth in Africa's economy is based on international integration in which domestic conditions for doing business are improved to attract foreign investments, while African countries endeavor to supply extracted natural resources and agricultural products. The African Development Bank, AfDB [4] report shows that manufacturing in Africa is weak, implying very small production of industrial products. Evidently, the present development is 
exogenic and heavily reliant on foreign demand for natural resources. In this paper, it is argued that SSA presently lacks endogenic growth in engineering and scientific research as the fulcrum for industrial development.

\section{Innovation Models}

Innovation entails the generation of new knowledge or ideas which should meet a societal need, followed by development of its technology leading to product manufacture for market consumption. The new knowledge generated may emanate from a discovery made during fundamental or applied research in SE\&T fields, and could fulfil a need or solve a problem in society. This category includes academic research conducted at HEIs and is often referred to as the Technology-Push model. An alternative process, the Market-Pull model occurs when a need arises in the market which inspires research and development (R\&D) to be conducted, during which a new product is developed to meet the market need. The main difference between these two models is initiation stage of the innovation. Scientific discovery is the primary initiator in the technology-push model, as opposed to the market-pull model, where the market need or demand initiates the technology development. With the technology-push model, the scientific basis of the technology is established through fundamental or applied research, then and only then may it be transformed into a market product. Both models follow endogenic and indigenous approaches, and are often applied in developed countries while it is indicated that these models of innovation may not apply to developing countries [5]. Clearly, for any of the models to become operative, there must be strong continuous research productivity in SE\&T fields. Absence of critical capacity implies lack of $R \& D$ resource including expert human resource for scientific research, along with necessary equipment and facilities. Whereas Africa has the advantage of possessing indigenous knowledge in niche areas related to culture and arts, it severely lacks core capacity in fundamental and applied scientific research of engineering and technology domains. As such, it is no surprise that the present trends of growth in SSA do not strongly feature manufacturing and domestically developed industrial products of engineering innovations.

In the present, African countries are perceived to be predominantly consumers of already existing technology, with little if at all, of their own new scientific creations. The existing technology is considered to be state-of-the-art knowledge and can be tyrannical, often overriding crudely innovated local or alternative technologies.

However, for African countries to become strongly competitive in the present global economy, it is evident that SSA must not only be receptive to established technologies but must also develop capacity to modify these existing technologies while aiming to create new innovations. Absence of domestic creation of new scientific knowledge and products is considered one of the key contributors to the current industrial under-development.

\section{Research Productivity}

Basic sciences, mathematical sciences and technological tools are spheres of knowledge that are applied in engineering science to design and produce products targeted at meeting societal needs. The beginning of the $21^{\text {st }}$ century seems to have raised optimism about potential development of Africa. The SSA sub-continent has the youngest population with $50 \%$ being 
under 25 years of age, which provides opportunity to develop and prune human capital for future development. Data shows that research output in SSA has doubled over the past decade, and its share of global research production has also increased from 0.44 to $0.72 \%$ over the same period. However, this volume of research from SSA is disproportionately low, and is not consistent with Africa's 12\% share of world population. Secondly, the research conducted in SSA is concentrated within the fields of medical and health sciences, while relatively less research is being done in engineering and technology.

Africa's research faces challenges of limited availability of research funding and shortage of researchers. Research expenditure among SSA countries is less than 1\%, the highest being Southern Africa, East Africa and some West African countries, spending between 0.51 to $1 \%$ of GDP. Using article citations as a measure of research quality, the highly citable articles are those found among the top $10 \%$ of the world total number of publications produced within a specific subject domain [6]. Fig. 1 gives the trends showing increase in the number of SSA articles that are cited among the top worldwide, rising from $8 \%$ in 2003 to $13 \%$ in 2012 . However, citation of engineering and technology articles in SSA is much lower, being in the range of 3 to $7 \%$. Clearly, engineering and technology in SSA lags behind the other major fields especially medical and health sciences, both in quantity and in quality [6].

Another useful indicator of R\&D is the filing of patents. With SSA contributing less than $1 \%$ of world research outputs, it can be expected that the patents generated are also low. Hardly any data concerning patents in SSA are readily available except in countries such as South Africa.

\section{Research Impacts}

Developing countries including Brazil, India, China, Malaysia, Vietnam etc. grapple with similar issues related to development, as does SSA. Like Africa, China too has had a tumultuous history over the past 100 years, associated with global politics and ideologies.

Yang [7] discusses in detail the different phases of Chinese history over the past 100 years as relating to its education. In the 1980's China, began making educational reforms aimed at being receptive to imported knowledge and improving it alongside indigenous knowledge. Research became the main theme and focus of the educational system. Between 1996 to 2000, China had increased its number of researchers to 30,144 . These reforms are seen to have promulgated its modern growth and ongoing development. 


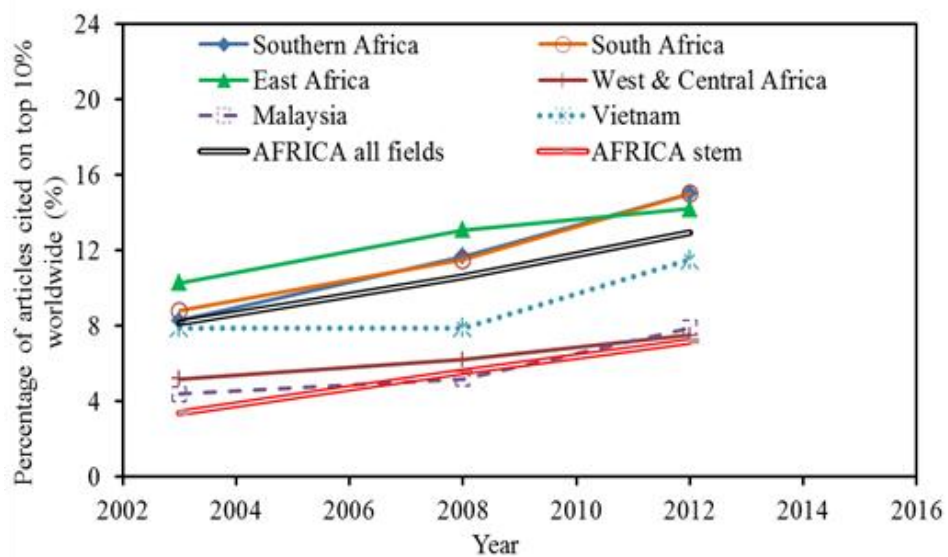

Fig. 1 Proportion of articles cited among the top 10\% worldwide [6]

Gazing back to history over the past 300 years, there is convincing evidence that modern industrial advancements are anchored upon scientific and industrial research, leading to generation of new ideas or improvement of existing technologies. These ideas often turn into industrial products for commercial exploitation. Most of the major world advances of the present time came about through this process. It was responsible for industrial growth or revolution in the UK during the $18-19^{\text {th }}$ century, and propelled the economies of Germany and USA during the $1^{\text {st }}$ and $2^{\text {nd }}$ halves of the $20^{\text {th }}$ century respectively [8]. Fig. 2 shows that there has been acceleration of research in China especially since 1993, overtaking India and most other developing countries, as indicated by the yearly number of published articles [8]. The observed research growth in China is pivotal to its mega-economic gains.

Research is known to be an essential stimulator of economic development, as it produces new ideas and products therefore creating wealth. Fig. 3 shows a strong correlation between economic growth and the number of articles published [9]. Increase in quantity of publications is associated with rise in GDP and vice versa. This implies that while research feeds its innovations into the industry, the benefit realised may also be fed back to increase the research output. Further correlations can be seen in Figs. 4 and 5, between GDP and the number of patents per country [9]. Generally, more patents are associated with greater GDP per capita of any given country. However, population density influences this trend, with countries that have a high density population showing relatively low GDP for a given number of patents while the less populated countries show a relatively higher GDP, as shown in Fig. 5. Overall, however, it is shown that producing more patents has a direct consequence on economic growth, leading to increase in GDP per capita.

It is quite important to recognize that research capacity is related to the number of researchers in possession of advanced qualifications, especially at doctoral level. Unfortunately, there are no data records of actively engaged $\mathrm{PhD}$ researchers in SSA but a grim picture is likely. 


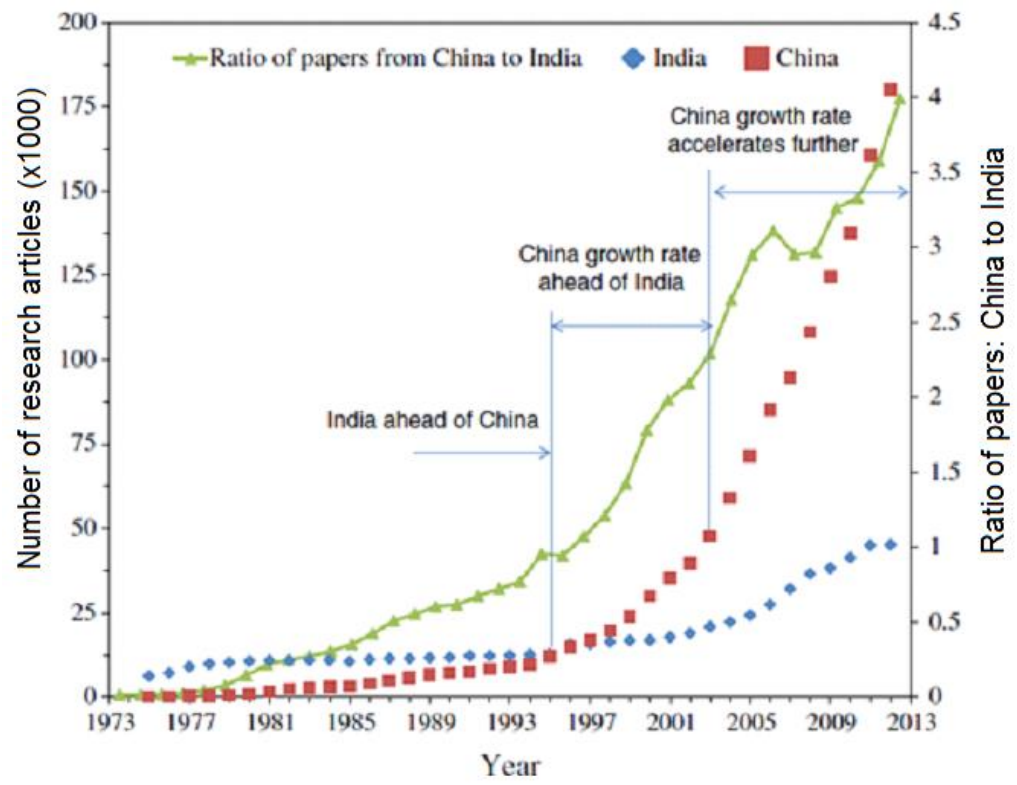

Fig. 2 Acceleration of China's research outputs [8]

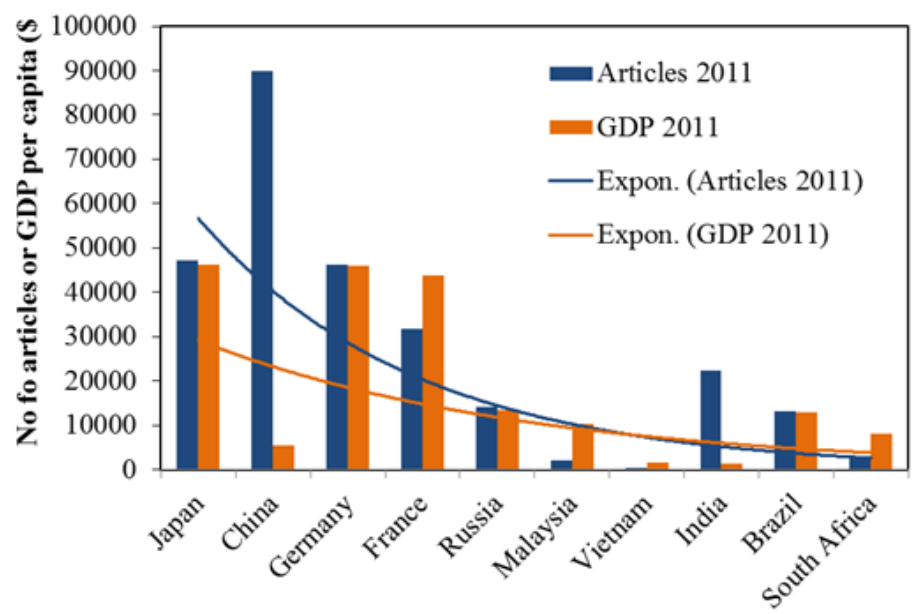

Fig. 3 Correlation between the article publications and gross domestic product (Constructed from [9]) 


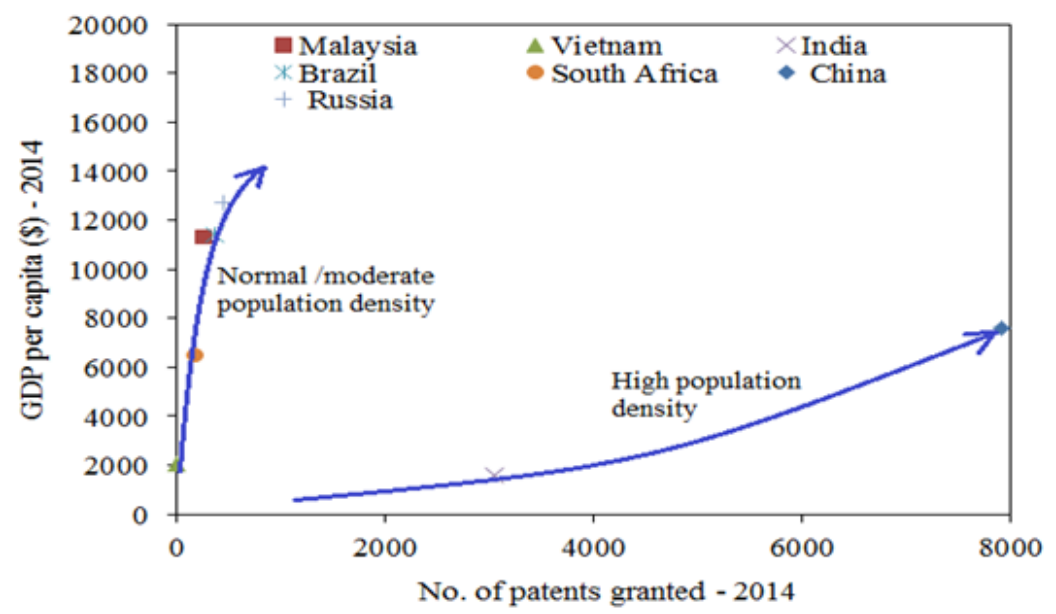

Fig. 4 Relationship between patents and GDP of developing countries (Constructed from [9])

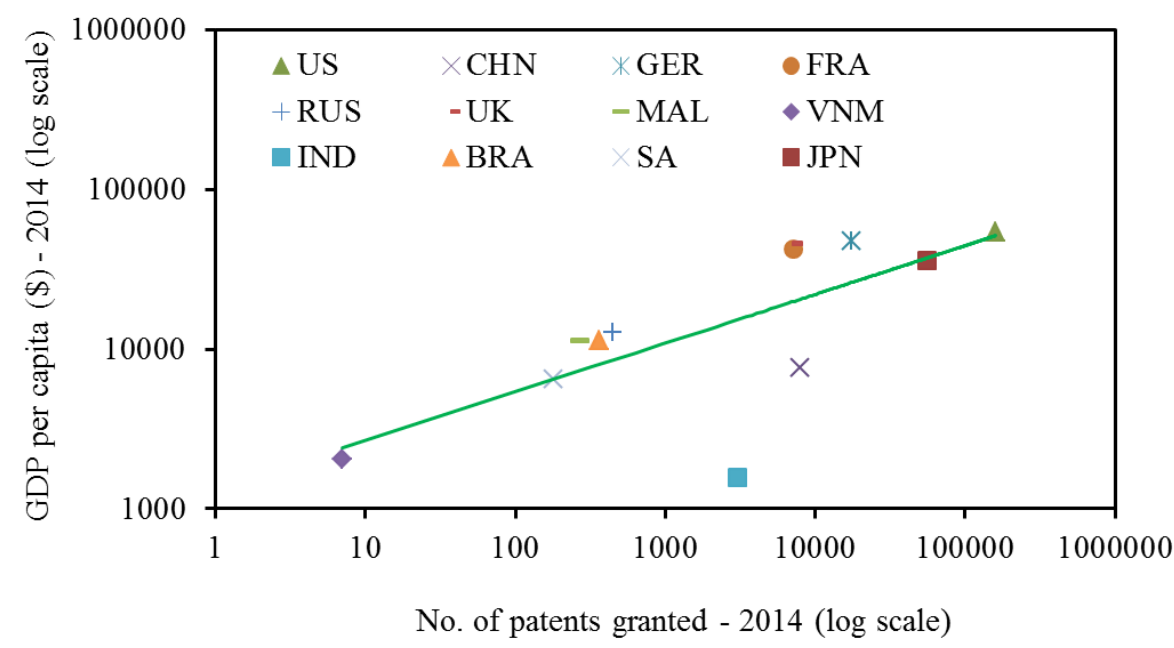

Fig. 5 Relationship between patents and GDP worldwide (Constructed from [9]) 


\section{Conclusion}

In the foregone discourse relating research, innovation and development, it is quite evident that there are correlations between research productivity and industrial development. The past technological advancements have come through mastery of existing scientific knowledge and innovating to create additional or new knowledge.

It was shown that high research productivity is directly related to industrial development. Also, direct correlation exists between the number of patents granted and GDP of a country. Growing the number of researchers and investing into research, more especially in Science, Engineering and Technology has a direct effect of promoting development, as evident in GDP increase with rise in the number of patents. What Africa now needs is acceleration of these aspects.

Acknowledgments. The study presented in this paper was funded by the National Research Foundation (NRF) of South Africa, IPRR Grant No. 96800. The author is grateful for the financial support given by NRF.

\section{References}

1. UNESCO: Engineering: issues, challenges and opportunities for development", Published in 2010 by the United Nations Educational, Scientific and Cultural Organization, 7, place de Fontenoy, 75352 Paris 07 SP, France. (C) UNESCO, 2010a. ISBN 978-92-3-104156-3

2. UNESCO, Trends in Tertiary Education: Sub-Saharan Africa, UNESCO Institute for Statistics, UIS fact sheet, UIS/FS/2010/10, December 2010b, 7p.

3. Ekolu S.O: On capacity and quality issues in engineering studies across Sub-Saharan Africa: Proceedings of the 6th African Engineering Education Association International Conference (AEEA2016), 20-22nd September 2016, Bloemfontein, South Africa.

4. AfDB, African Economic Outlook: African Development Bank (AfDB), 2015, 38p. http://www.africaneconomicoutlook.org/

5. Wang V. and Carayannis E. G.: Promoting balanced competitiveness strategies of firms in developing countries, Springer, eBook ISBN 978-1-4614-1275-5, 2012, 128p.

6. WorldBank: A decade of development in SubSaharan African science, technology, engineering and mathematics research, 2013.

www.worldbank.org/Africa/stemresearchreport/

7. Yang R.: Internationalisation, indigenization and educational research in China, AARE Annual Conference, 2004, Mebourne, Australia.

8. Panat R.: On the data and analysis of the research output of India and China: India has significantly fallen behind China", Mechanical Engineering, School for Engineering of Matter, Transport and Energy, Arizona State University, Tempe, AZ 85287, USA, February 2014, 11p.

9. WorldBank Data: Sub-Saharan Africa, (2014), http://data.worldbank.org/region/SSA. Accessed 25 Mar 2016. 